\title{
Perceptions of an integrated curriculum among dental students in a public university in Saudi Arabia
}

\author{
Khulood Sami Hussein
}

Ph.D., Assistant Professor, Department of Physiology, Faculty of Medicine, King Abdulaziz University, Jeddah, Saudi Arabia

\section{Type of article: Original}

\begin{abstract}
Background: Being aware of the limits of traditional discipline-based education, the Faculty of Dentistry at King Abdulaziz University (KAU) tasked basic medical science faculty members with developing a new integrated curriculum for undergraduate dental students to be applied in the 2014/2015 academic year.

Objective: To determine the students' perceptions of the restructured curriculum and elicit student suggestions for improvement.

Methods: A questionnaire was distributed to all first-year dental undergraduate students $(n=192)$ enrolled in the academic year of 2014/2015. The questionnaire was written in English and included standard questions designed to determine student satisfaction toward the restructured curriculum. The different variables in the study were analyzed with descriptive statistics and the significance level was measured by SPSS version 16, using the descriptive statistics and Chi-square test.

Results: At the end of the first year, a large majority of students rated their overall experience with the course as good or excellent and agreed that the connection between basic and clinical sciences was made clear in the dental relevance sessions. In general, students' experience with the instructors was positive. However, although most students felt that assessment methods were fair and reflected the curriculum, the overall success rate was lower than that of the previous academic year $(2013 / 2014)(\mathrm{P}=0.002)$, when the traditional-discipline based curriculum was still in place.

Conclusion: Having completed the first step of the restructuring of the first-year basic science dental curriculum, our plan for the next phase in the curriculum integration process is to increase inter-course and inter-topic integration and supplement the delivery of the course material with more clinical case scenarios.

Keywords: Integrated curriculum, Perception, Saudi Arabia, Undergraduate students
\end{abstract}

\section{Introduction}

The Faculty of Dentistry at King Abdulaziz University (KAU), in Jeddah, Kingdom of Saudi Arabia, is a public school admitting only Saudi students to the Bachelor of Dental Surgery (BDS) degree (after an initial preparatory general science year). It is one of the largest public dental schools in Saudi Arabia. The dental school at KAU has an annual based system, like all dental schools in Saudi Arabia, with two semesters per academic year in a five-year program, followed by one-year compulsory internship training (1). The first two years of the BDS educational curriculum focuses on the basic medical sciences while subsequent years focus on the clinical sciences and the clinical training. In this discipline-based model, the basic medical science courses are taught in isolation with very little integration, leaving students to make connections between basic sciences, the mastery of skills and clinical care of patients from didactic material with many large gaps. As the limits of discipline-based education have become clear, basic medical science faculty members were tasked first with reviewing the basic science curriculum for undergraduate dental students, followed by planning and implementing changes to the curriculum. It was decided to limit this process of evaluation and change to the first-year curriculum as an initial phase in an ongoing process of restructuring the whole curriculum. Several administrative, logistical, and conceptual challenges arise when moving

\section{Corresponding author:}

Assistant Professor Dr. Khulood Sami Hussein, Department of Physiology, Faculty of Medicine, King Abdulaziz University, Jeddah, Saudi Arabia. Tel.: +966505358188, Email: Khussein@kau.edu.sa

Received: April 02, 2017 , Accepted: May 05, 2017, Published: July 2017

iThenticate screening: May 05, 2017, English editing: June 01, 2017, Quality control: June 12, 2017

(C) 2017 The Authors. This is an open access article under the terms of the Creative Commons Attribution-NonCommercialNoDerivs License, which permits use and distribution in any medium, provided the original work is properly cited, the use is non-commercial and no modifications or adaptations are made. 
from a discipline-based curriculum to a more integrated model $(2,3)$. One of the challenges we had to address was expected resistance from the faculty to curricular change related to instruction, assessment, evaluation, and authority. The first step involved extensive discussions among departments, course directors, and individual faculties to reach a consensus by all parties that curriculum restructuring was necessary and would give students better educational outcomes. All participants also agreed that for these curriculum changes to be feasible, the transition process to a fully integrated curriculum should be carried out in an incremental manner. The traditional courses in the initial stage remained intact but as the various systems in the body (e.g. cardiovascular, respiratory, gastrointestinal, etc.) were presented, the anatomy, biochemistry, physiology, etc., related to each system were also taught $(4,5)$. Deciding on the syllabus, course objectives, sequence of teaching, detailed course content and method of student assessment, required extensive interaction and agreement among the parties involved. Clinical examples and problems related to dental practice were also chosen to relate the basic scientific knowledge to patients and real life clinical situations. These examples were carefully selected with input from a dental clinician and were based on commonalities across the curriculum objectives and the Saudi Arabian context. The anatomy, histology, embryology, and physiology departments at the KAU Faculty of Medicine and the oral and maxillofacial surgery department at the Faculty of Dentistry worked together to create the content of a new discipline named 'Structure and function of body systems'. Student performance was assessed through a single, multi-course exam at the end of each block of material. These exams consisted of multiple-choice questions and were delivered on paper, with students recording their answers on a Scantron ${ }^{\circledR}$ form (Scantron Corp, Eagen, MN). These end-of-theme exams were designed so that student achievement in individual course objectives could be recorded. In addition, each course had its own final exam and students took an Object Structured Practical Examination (OSPE). At the end of the academic year, students were given a separate grade for each course. The introduction of the restructured first year dental curriculum took place in September 2014 (at the beginning of the academic year of 2014/2015). In order to evaluate the new program and identify any shortcomings in the new curriculum, this study was carried out to explore KAU dental students' views of the reformed curriculum and determine what future improvements could be made.

\section{Material and Methods}

This questionnaire-based study was carried out at the end of the academic year 2014/2015, at the conclusion of the course. All first-year dental students, male and female $(\mathrm{n}=192)$ enrolled at the Faculty of Dentistry, KAU in Jeddah, Saudi Arabia were included in the study. The primary outcome measure was the level of satisfaction of dental students with the newly introduced curriculum. Additionally, the study sought student suggestions for future improvements of the program. The questionnaire was designed by the researchers, based on a literature review and tailored to the current context (6-8). The questionnaire was written in English and included standard questions aimed at determining the students' level of satisfaction toward the restructured curriculum. The first section collected demographic data of each student such as gender, age, and GPA at the end of the preparatory year. The subsequent sections of the questionnaire consisted of questions carefully derived from other similar questionnaires consistent with the objectives of the study. Most of the questions used a 5-point Likert scale (1=strongly agree, $2=$ agree, $3=$ neutral, $4=$ disagree, and $5=$ strongly disagree). Some questions related to the overall rating asked students to use the descriptors excellent, good, average, and poor. Students were also encouraged to write comments identifying problems and suggesting improvements. Before distributing the questionnaires to all first-year dental students, the investigator (the Physiology course director) informed them about the purpose of the study and assured them of confidentiality. Students were informed that participation was voluntary and anonymous and that their grades would not be affected whether or not they chose to participate in the study. In order to reduce skewed answers due to different understandings of questions, the investigator explained the meaning of each question to the participants. Students were also encouraged to respond to the questions honestly. The questionnaire and a cover consent letter were uploaded on the web using Google Docs (Google Inc., Googleplex, Mountain View, California, USA). At the end of the year, students received an email prompt to proceed to the evaluation website and complete the curriculum evaluation. One questionnaire per email address was allowed in order to avoid multiple submissions by one respondent. Completion of the survey was considered implied consent. All responses were anonymous and no identifiable information was collected. The different variables in the study were assessed with descriptive analysis and the significance level was measured using the Chi-square test. Statistical Package for Social Sciences (SPSS version 16) was used and the data were analyzed using frequencies, percentages, means and standard deviations. Statistical analysis was completed after obtaining the final examination scores. 


\section{Results}

In September 2014, 192 students entered the Faculty of Dentistry at KAU, and 181 of them participated in the study, giving a response rate of $94 \%$. Out of 181 respondents, there were 81 males $(44.8 \%)$ and 100 females $(55.2 \%)$ aged between 19 and 20 years (mean age $=19.5$ years), and $120(66.3 \%)$ had a GPA of 4.75/5 or above at the end of the preparatory year. Table 1 shows descriptive variables of the sample. The fundamental research question centered on the level of satisfaction dental students had with the restructured curriculum; therefore, a graded system was used to evaluate the respondents' opinions on any given question, ranging from 'strongly agree' to 'strongly disagree'. For the sake of simplicity, the satisfaction rates have been presented as a combination of male and female views since their views on the curriculum did not differ significantly. Similarly, responses of 'strongly agree' and 'agree' have been combined, as have 'strongly disagree' and 'disagree'. At the end of the course, $81 \%$ ( $\mathrm{n}=148$ out of 181) of the participants rated their overall experience with the course as excellent or good. The learning objectives of the course were unclear to only $6.6 \%(\mathrm{n}=12)$ of the participants. Seventy seven percent $(\mathrm{n}=140)$ agreed or strongly agreed with the statement "Redundancy in the content was minimal". The majority $(93.9, \mathrm{n}=170)$ agreed that dental relevance sessions show the relation between basic and clinical sciences. The majority of the group $(71.8 \%, \mathrm{n}=130)$ agreed that assessment methods were fair and reflected what was taught, $55.2 \%(\mathrm{n}=100)$ were dissatisfied with the frequency of examination, and $91.2 \%(\mathrm{n}=165)$ were satisfied with the post assessment feedback given by the instructor. Eighty seven percent $(\mathrm{n}=158)$ accepted the statement "Faculty wanted us to learn and ask questions to make sure we understand" and most of the students $(76.8, \mathrm{n}=139)$ believed "The instructor used examples/personal experiences to help me understand a point". Most of the students $(n=169)$ were satisfied with the post assessment feedback given by the instructor. Ninety three percent $(n=168)$ rated their overall experience with the instructor as excellent or good. The overall success rate was higher (98.6\%) during the academic year of 2013/2014 when compared to that of 2014/2015 (95.8\%). The percentage of students who failed the course was significantly higher in $(2014 / 2015)$ (Table 2).

Table 1. Descriptive variables of the sample

\begin{tabular}{|l|l|}
\hline Academic year & $2014 / 2015$ \\
\hline Number of students & 192 \\
\hline Number of responding & 181 \\
\hline Response rate & $94 \%$ \\
\hline Male $\%$ & $44.8 \%$ \\
\hline Female \% & $55.2 \%$ \\
\hline
\end{tabular}

Table 2. Students' final scores in physiology final exam

\begin{tabular}{|c|c|c|c|}
\hline Grade & 2013/2014; n (\%) & 2014/2015; n (\%) & Test of significance \\
\hline A & $37(24.7)$ & $46(23.9)$ & \multirow{6}{*}{$\begin{array}{l}\text { Chi-square test }=17.021 \\
\text { p-value }=0.002\end{array}$} \\
\hline B & $65(43.3)$ & $53(27.6)$ & \\
\hline $\mathrm{C}$ & $42(28)$ & $64(33.3)$ & \\
\hline $\mathrm{D}$ & $4(2.7)$ & $21(10.9)$ & \\
\hline E & $2(1.3)$ & $8(4.2)$ & \\
\hline Overall success rate & 148 (98.6) & $184(95.8)$ & \\
\hline
\end{tabular}

\section{Discussion}

Globally, the curricula in various dental faculties have undergone periodic modifications as efforts are made to improve outcomes in dental education in response to changes in the prevalence and severity of oral diseases and better treatment expectations among the general public $(9,10)$. In the academic year 2014/2015, the restructured basic science component of the first-year dental curriculum was introduced and problem sessions with clinicallyrelevant dental issues were incorporated into the subject curriculum to integrate basic and clinical sciences. Another substantial change was the introduction of a single, coordinated, multi-course examination for each block of curricular material. As the students are the stakeholders who experience the curricular changes firsthand, their feedback is essential (11), and many agree that student opinion is valuable in the restructuring of the curriculum (12) and making it more satisfactory and beneficial. In the long term, the goal of the restructured first-year dental program is to transition from a discipline-based curriculum to an integrated one. In the initial phase of this transition, the objectives were to: 1) reduce unnecessary redundancy between courses, 2) reduce the number of lectures, 3) increase the time available for students to engage in self-directed learning, and 4) place less emphasis on compartmentalized teaching and testing strategies (13). Although our main goal was to integrate basic and clinical 
sciences, we realized that this integration could only be achieved by introducing different pedagogical strategies. In other words, besides introducing the reformed first-year dental curriculum, it was necessary to introduce new methodologies to maximize its effectiveness such as small group discussions to solve problems and combination laboratory/classroom activities. This study presents the promising results of a survey of the first cohort of first-year dental students in a public dental university of a developing country like Saudi Arabia to assess their satisfaction with the restructured basic sciences curriculum. Factors impacting the curricular activities and satisfaction rate among students have been noted. Recommendations for improvements were also sought from the students as learners' opinions are invaluable in any ongoing evaluation of the educational process. The high response rate of $94 \%$ indicates that students appreciated the chance to reflect on their experiences in the course and give feedback on what they saw as the most and least valuable aspects. The majority of the participants felt that their responses would make a difference in improving weaknesses in the curriculum. Our response rate is higher than that seen in earlier studies of students' opinions on changes in their undergraduate education (14-16), although response rates as low as $33 \%$ have been considered adequate for conclusions to be drawn (17). Ineffective learning experiences are often characterized by problems with the organization or presentation of course material. The study showed that the learning objectives of the course were unclear to only $6.6 \%$ of the students. This is similar to the study conducted by Soliman et al. which, showed that $5.8 \%$ of the students stated that the learning objectives were unclear (18). Overall, the students' rating of the course seemed to be positive with $81 \%$ of the students rating the course as excellent or good. Our findings are comparable with some previous studies (18-20). However, other previous studies report an overall satisfaction rate of $28.4 \%$ (21). A culture where a learning environment promotes a good relationship between students and professor can create a place where students are able to ask questions and learn with possible mistakes. This can help develop a good professional atmosphere $(22,23)$. The majority of the students agreed that the instructor's attribute and behavior was positive. "Approachability, openness to questions, and willingness to give guidance and feedback were able to motivate me as a student". "Faculty wanted us to learn and ask questions to make sure we understand". "Enthusiasm for the subject matter, patience, and a sense of humor were displayed by physiology instructors". In the classroom, these instructors would often use personal stories or clinical cases to stimulate discussion and provoke thought. The bottom line is that curricular reform is about change. One of the current reasons for making changes is to reduce unnecessary redundancy between courses. Curricular redundancy can be a major problem for medical schools, especially those with an integrated curriculum (24). Although some redundancy is desirable (e.g. intentional efforts aimed at reinforcing prior content), many forms of redundancy are not. More than three-quarters (77.3\%) of the participants in this study agreed that redundancy in the curriculum was minimal. Undesirable redundancy can result in the loss of valuable instruction time and could seep into a curriculum in a variety of ways, including, but not limited to, a lack of communication among instructors or course offerings that present content that is too similar. Learners are willing to invest time learning a topic only after they understand the topic's relevance (25). In medical education, basic science details are difficult to connect to clinical scenarios for novice students with limited or no clinical exposure; this challenge is overcome by linking basic science material to clinical problems, often through patient-based or case-based learning. The perception of students regarding the dental relevance sessions was positive. A high percentage of the students $(93.9 \%)$ agreed that dental relevance sessions led to better connection between basic and clinical science subjects and more profound understanding of the subjects, although the dental terminology was hard to understand at the beginning of the sessions. Their positive impression of these sessions could be attributed to the effectiveness of these clinical examples in making connections among concepts through integrated presentation of material. There are two ways that integration can enhance long-term retention and deeper understanding (26). In a recent study carried out by Al-Drees et al, researchers showed that a problem-based learning system helps develop student skills (27) and their knowledge was retained and easily recalled in comparison with other teaching methods (28). Callis et al. reported that students who enrolled in case-based learning demonstrated a greater ability to apply basic science principles to a clinical scenario when compared to traditional lecture-based students. Consequently, this led to an increase in the student's skills in the areas of communication and hypothesis generation, which are necessary for interacting with other health professionals (29).

Assessment is an integral tool with several functions; it can give feedback to learners regarding their strengths and weaknesses, help instructors evaluate the effectiveness of a given approach, and highlight limitations of the approach (30). Before the curriculum was restructured, separate exams were given for each course during week-long exam periods held every four to six weeks throughout the academic year. The restructured program involved several changes in the way exams were constructed and delivered. Most significantly, the various departments involved, worked together to create a single, multi-course exam for each block of material (theme). Questions on these exams came from all courses taught during the module covered. Feedback was given to students after each assessment to 
enhance student achievement. Because of this shift to a single exam, only one day was needed instead of a whole week, as was the case with the previous curriculum. This meant more time for self-directed learning, which was often scheduled in the days before the exams. At the end of each term, summative assessment was conducted to assess the students' competencies. One problem with the restructured curriculum, which became obvious by the end of the first term, was lower student performance in the Physiology course. At that time, approximately three quarters of the Physiology course had been taught, and it was clear that overall student performance on the Physiology portion of the in-course examinations had been adversely affected by the restructuring. This was attributed to the fact that the material was compressed into a much shorter time span than it was prior to restructuring. The first term is a time when dental students are still adjusting to the level of intensity required, so having to master almost $75 \%$ of the Physiology curriculum in that period seemed to be too challenging. Before restructuring, the same curriculum was distributed equally over two terms. In response to the lower-than-expected student performance, the Physiology faculty implemented directed learning sessions involving problem solving and small group discussions, and a poster activity covering previous content areas such as cardiovascular and respiratory themes, the outcomes of which were not met by the majority of the students. These efforts resulted in an overall success rate on the Physiology subject examination comparable to that of the previous year. The following positive outcomes were achieved by integrating basic and clinical knowledge in the KAU dental school curriculum: less duplication of skills and concepts across subjects; more clinical relevance for students; and better preparedness of students for work in clinical settings. Clearly, integration of these four basic science courses (anatomy, histology, embryology, and physiology) is just the first step towards full integration of the curriculum. Many developed countries have transitioned to an integrated curriculum. One of our challenges was implementing such a curriculum in a developing country. We are still developing our integrated model, but our initial evaluation of the new curriculum, with the various approaches for teaching the basic sciences, including lectures, small-group discussions, laboratory activities, and self-directed learning, is that it facilitates the acquisition of necessary concepts of basic sciences and more importantly, encourages life-long learning strategies. This study has an important implication, which is the recognition of the important role that students play in the curriculum evaluation process. The in-depth and candid responses in the questionnaires completed by the students may have been due to the timing of the evaluation: at the end of the course and after the final assessment. This robust student feedback encompassed dual strengths of the study. First, more than three-quarters of the students completed the questionnaire even though they had just completed their final assessment, showing their commitment. In addition, students took the time to give comments and suggestions, indicating their willingness to give constructive feedback on the new curriculum. As a result of their thoughtful responses, important aspects of the curriculum have been identified for modification and additional faculty development. The major limitation of this study was the absence of a control group.

\section{Conclusions}

We have completed the initial stage of what we anticipate being a multi-phase process to restructure our first-year basic science dental curriculum. Approaching curriculum restructuring in a step-by step manner was a significant factor in our success, as it encouraged interaction and collaboration among various course directors and the basic science faculty. It was also instrumental in overcoming expected resistance to change, and creating an outcome everyone was invested in. Needless redundancy and topic duplication were eliminated by having frequent meetings and course director discussions about the re-organization of topics. With extra time freed up in the curriculum, there was more time for self-directed learning activities. The cross-course alignment of topics and the multi-course combined exams resulted in higher integration and less compartmentalization of the curriculum. With its focus on what the first cohort of students thought of the restructured first year dental curriculum of the Faculty of Dentistry at $\mathrm{KAU}$, this study presents valuable and important data for curriculum revision and improvement. The projected next step in the curriculum integration process is to increase inter-course and inter-topic integration and implement more clinical case scenarios in the delivery of the course material. Other likely steps are to include a greater focus on topics which are directly relevant to dental practice, add more dental relevance sessions, and introduce online assignments for self-directed student learning.

\section{Acknowledgments:}

The author is very grateful to Professor Hala Mokhtar, Dental Surgery Department at KAU for sharing her pearls of wisdom during this research as well as for her comments that greatly improved the manuscript. A special thanks to all the students who participated in the study.

\section{Conflict of Interest:}

There is no conflict of interest to be declared. 


\section{References:}

1) Abdulghani H. Admission criteria for Saudi Health Colleges: The current status and a literature review. Article in Medical Channel. 2009; 15(3): 18-21.

2) Prince KJ, Van De Wiel M, Scherpbier AJ, Can Der Vleuten CP, Boshuizen HP. A qualitative analysis of the transition from theory to practice in undergraduate training in a PBL medical school. Adv Health Sci Educ Theory Pract. 2000; 5(2): 105-16. doi: 10.1023/A:1009873003677. PMID: 12386467.

3) Klement BJ, Paulsen DF, Wineski LE. Anatomy as the Backbone of an Integrated First Year Medical Curriculum: Design and Implementation. Anat Sci Educ. 2011; 4(3): 157-69. doi: 10.1002/ase.217. PMID: 21538939, PMCID: PMC3263510.

4) Drake RL. A retrospective and prospective look at medical education in the United States: trends shaping anatomical sciences education. J Anat. 2014; 224(3): 256-60. doi: 10.1111/joa.12054. PMID: 23600681, PMCID: PMC3931536.

5) Fishleder AJ, Henson LC, Hull AL. Cleveland Clinic Lerner College of Medicine: an innovative approach to medical education and the training of physician investigators. Acad Med. 2007; 82(4): 390-6. doi: 10.1097/ACM.0b013e318033364e. PMID: 17414197.

6) Ozan S, Karademir S, Gursel Y, Taskiran HC, Musal B. First graduates' perceptions on a problem-based and task-based learning curriculum. Educ Health (Abingdon). 2005; 18(2): 256-71. doi: 10.1080/13576280500148007. PMID: 16009619.

7) Sirous S, Ashourian V, Adhamian P. Survey on student's attitude of medical school in Isfahan Medical University toward counseling and guidance the process. Proceeding of the 11th Iran National Congress on Medical Education. Tehran; Iran University of Medical Science; 2010: 255.

8) Mehr SE, Hassanzadeh G, Zahmatkesh M, Seyedian M, Arbabi M, Mirzazadeh A, et al. Medical students' viewpoint regarding the integrated module of basal ganglia. Acta Med Iran. 2011; 49(11): 753-9. PMID: 22131247.

9) Junges R, Stello RS, Portella FF, Rosing CK, Samuel SM. Impact of the implantation of a new curriculum in the process of learning in a Faculty of Dentistry in Brazil. Braz Oral Res. 2011; 25(6): 478-84. doi: 10.1590/S1806-83242011000600002. PMID: 22147226.

10) Rosing CK, Oppermann RV, da Silva DT, Deon P, Gjermo P. Student's appraisal of their dental education related to basic sciences learning: a comparison of four curricula in Norway and Brazil. Rev Odonto Cienc. 2008; 23(3): 234-7.

11) Mclean M, Gibbs T. Twelve tips to design and implementing a learner centered curriculm; Prevention is better than cure. Med Teach. 2010; 32(3): 225-30. doi: 10.3109/01421591003621663. PMID: 20218837.

12) Tyler IV, Hau M, Buxton JA, Elliott LJ, Harvey BJ, Hockin JC, et al. Canadian medical students' perceptions of public health education in the undergraduate medical curriculum. Acad Med. 2009; 84(9): 1307-12. doi: 10.1097/ACM.0b013e3181b189b4. PMID: 19707078.

13) Malik AS, Malik RH. Twelve tips for developing an integrated curriculum. Med Teach. 2011; 33(2): 99104. doi: 10.3109/0142159X.2010.507711. PMID: 20874013.

14) Farge P, Virieux J, Doury J. Student satisfaction with curriculum modifications in a French dental school. Eur J Dent Educ. 2000; 4(3): 112-7. doi: 10.1034/j.1600-0579.2000.040304.x. PMID: 11168473.

15) Mcinerney P, Green-Thompson LP, Manning D. Experiences of graduating students from a medical program five years after curricular transformation: A descriptive study. African Journal of Health Professions Education. 2013; 5(1): 34-6. doi: 10.7196/ajhpe.210.

16) Rehman R, Iqbal A, Syed S, Kamran A. Evaluation of integrated learning program of undergraduate medical students. Pak J Physiol. 2011; 7(2): 37-41.

17) Levy G, d'Ivernois JF, Brun D, Gagnayre R. A French dental school program appraisal by alumni of 5-9 years standing. Eur J Dent Educ. 1997; 1(2): 70-7. doi: 10.1111/j.1600-0579.1997.tb00015.x. PMID: 9567904.

18) Soliman MM, Al-Swat K, Alsaif F, Al-Nassar S, Bayoumi N, Leheta O, et al. Medical students' perception of the reformed medical curriculum at King Saud University. J Health Spec. 2016; 4: 46-51. doi: 10.4103/1658-600X.173838.

19) Dehghan M, Anvari M, Hosseini Sharifabad M, Talebi A, Nahangi H, Abbasi A, et al. The viewpoints of medical students in Yazd University of Medical Sciences toward horizontal integration teaching method in anatomical sciences courses. Strides Dev Med Educ. 2011; 8(1): 81-7.

20) Eyal L, Cohen R. Preparation for clinical practice: A survey of medical students' and graduates' perceptions of the effectiveness of their medical school curriculum. Med Teach. 2006; 28(6): 162-70. doi: 10.1080/01421590600776578. PMID: 17074696. 
21) Jalili M, Mirzazadeh A, Azarpira A. A survey of medical students' perceptions of the quality of their medical education upon graduation. Ann Acad Med Singapore. 2008; 37(12): 1012-8. PMID: 19159034.

22) Victoroff KZ, Hogan S. Students' perceptions of effective learning experiences in dental school: A qualitative study using a critical incident technique. J Dent Educ. 2006; 70(2): 124-32. PMID: 16478926.

23) Ho MT, Tani M. What medical students value from their teachers. Aust Health Rev. 2007, 31(3): 358-61. doi: 10.1071/AH070358. PMID: 17669057.

24) Reynolds R, Hasit C, Ito T, Keller R, Romrell L, Cameron T. Mapping medical education curricula. Presentation at the AAMC 2013 Annual Meeting. Philadelphia: PA; 2013.

25) Kaufman DM, Mann KV. Teaching and learning in medical education: How theory can inform practice, in Understanding medical education: Evidence, Theory and Practice. Wiley-Blackwell, Oxford, UK. 2010; 730. doi: 10.1002/9781444320282.ch2.

26) Nyquist JG, Jubran R. How learning works: Seven research-based principles for smart teaching. J Chiropr Educ. 2012; 26(2): 192-3. doi: 10.7899/JCE-12-022. PMCID: PMC3557656.

27) Al-Drees AA, Khalil MS, Irshad M, Abdulghani HM. Students' perception towards the problem based learning tutorial session in a system-based hybrid curriculum. Saudi Med J. 2015; 36(3): 341-8. doi: 10.15537/smj.2015.3.10216. PMID: 25737178, PMCID: PMC4381020.

28) Elimam M, Mohammed A. Perceptions of Undergraduate Students about Three Teaching Methods; Lectures, Practical and Problem Based Learning Sessions. Education Journal. 2015; 4(1): 15-9.

29) Callis AN, McCann AL, Schneiderman ED, Babler WJ, Lacy ES, Hale DS. Application of Basic Science to Clinical Problems: Traditional vs. Hybrid Problem-Based Learning. J Dent Educ. 2010; 74(10): $1113-24$. PMID: 20930242.

30) Pedersen S, Williams D. A Comparison of assessment practices and their effects on learning and motivation in a student-centered learning environment. J Edu Multimedia and Hypermedia. 2004; 13(3): 283-306. 